\title{
Cytoplasmic expression of epithelial cell transforming sequence 2 in lung adenocarcinoma and its implications for malignant progression
}

\author{
Zeinab Kosibaty ${ }^{1} \cdot$ Yoshihiko Murata $^{2} \cdot$ Yuko Minami $^{3} \cdot$ Tomoko Dai $^{1} \cdot$ Junko Kano $^{2} \cdot$ Ryota Matsuoka $^{2} \cdot$ \\ Noriyuki Nakano ${ }^{2} \cdot$ Masayuki Noguchi $^{2}$
}

Received: 8 March 2018 / Revised: 14 August 2018 / Accepted: 20 August 2018 / Published online: 12 December 2018

(c) United States \& Canadian Academy of Pathology 2018

\begin{abstract}
Epithelial cell transforming sequence 2 (ECT2), a guanine nucleotide exchange factor, is predominantly localized in the nucleus of non-transformed cells and functions to regulate cytokinesis. ECT2 is also localized in the cytoplasm of cancer cells. Aberrant cytoplasmic expression of ECT2 is thought to drive tumor growth and invasion. In this study, we investigated the cytoplasmic expression of ECT2 and its prognostic and biological significance in lung adenocarcinoma. Western blotting of cellular fractions from the nucleus and cytoplasm was performed to determine the subcellular localization of ECT2 in lung adenocarcinoma cell lines. The cytoplasmic expression of ECT2 in 167 lung adenocarcinomas was evaluated by immunohistochemistry and its clinical significance was examined using Kaplan-Meier curves and Cox regression analysis. Scraping cytology specimens of 13 fresh lung adenocarcinomas were used to assess the subcellular localization of ECT2 and its phosphorylation at Thr790 (P-ECT2(T790)). We found that ECT2 was localized in both the nucleus and cytoplasm of lung adenocarcinoma cell lines and tumor tissues. Cytoplasmic expression of ECT2 was detected by immunohistochemistry in $83(50 \%)$ of the lung adenocarcinomas, and was found to increase during cancer progression. It was expressed in $30(29 \%)$ small adenocarcinomas $(\leq 2 \mathrm{~cm}$ in diameter) and $53(82 \%)$ advanced adenocarcinomas ( $>2 \mathrm{~cm}$ in diameter). Cytoplasmic positivity for ECT2 was associated with a poor outcome in terms of both disease-free and overall survival (both $P<0.001$ ), and was an independent prognostic factor for overall survival $(P=0.025)$. Immunocytochemical staining for P-ECT2(T790) demonstrated cytoplasmic and membrane positivity in Calu-3 cells and scraping cytology specimens. Positive P-ECT2 (T790) staining was correlated with cytoplasmic ECT2 expression in 6 of 13 scraped cytology specimens tested. In conclusion, our findings indicate that cytoplasmic ECT2 expression could promote the malignant progression of lung adenocarcinoma and may represent a potent therapeutic target for patients with lung adenocarcinoma.
\end{abstract}

Electronic supplementary material The online version of this article (https://doi.org/10.1038/s41374-018-0142-4) contains supplementary material, which is available to authorized users.

$\triangle$ Masayuki Noguchi

nmasayuk@md.tsukuba.ac.jp

1 Doctoral Program in Biomedical Sciences, Graduate School of Comprehensive Human Sciences, University of Tsukuba, Ibaraki, Japan

2 Department of Pathology, Faculty of Medicine, University of Tsukuba, Ibaraki, Japan

3 Department of Pathology, National Hospital Organization, Ibaraki Higashi National Hospital, Ibaraki, Japan

\section{Introduction}

Lung adenocarcinoma is the most common subtype of lung cancer, accounting for approximately $35 \%$ of all lung cancers [1]. It is thought to progress in a stepwise manner from adenocarcinoma in situ (AIS) to minimally invasive adenocarcinoma (MIA) and invasive adenocarcinoma [2]. Patients with lung adenocarcinoma harbor unique genetic alterations [3], such as activated oncogenes (EGFR and $K R A S)$ and a translocated $A L K$ gene [4-6]. However, these molecular changes including mRNA and protein overexpression, alterations of copy number, somatic mutations, and DNA methylation have been mainly analyzed in advanced adenocarcinomas. Despite recent advances in diagnostic and therapeutic strategies, patients with advanced adenocarcinomas still suffer frequent treatment failure and 
disease progression [7]. We have previously examined the genetic and epigenetic alterations occurring in early-stage lung adenocarcinoma, and have found that several genes, such as stratifin, IGBP1, OCIAD2, and epithelial cell transforming sequence 2 (ECT2), show differences in their expression between in situ adenocarcinoma and early invasive adenocarcinoma.

The Rho family GTPases proteins are known to regulate a wide range of cellular processes including changes in cell morphology, cell proliferation, and gene expression. These enzymes are regulated through switching between an inactive GDP-bound form and an active GTPbound form. Guanine nucleotide exchange factors (GEFs) can catalyze the exchange of Guanosine diphosphate (GDP) for Guanosine triphosphate (GTP) on Rho family GTPases proteins, allowing them to trigger downstream signaling cascades. Overexpression of Rho family GTPases proteins is frequently observed in cancers, and such overexpression is involved in tumorigenesis $[8,9]$. Recently, we found that the ECT2 gene was amplified in early invasive lung adenocarcinoma, and that overexpression of this protein was correlated with poorer patient survival [10]. ECT2 is a GEF for Rho family GTPases proteins, especially RhoA, Rac1, and Cdc42 [11, 12]. ECT2 overexpression has been reported in various types of cancer, including those of the lung, esophagus, ovary, and brain, and shows tumorigenic activities [1315]. ECT2 consists of a C-terminal GEF domain that catalyzes its GEF activity, an N-terminal domain that regulates its GEF activity and localization, and a central S domain that has two nuclear localization signals (NLSs) required for ECT2 nuclear localization [16, 17]. In normal cells, ECT2 is localized in the nucleus during interphase, becomes distributed to the cytoplasm upon breakdown of the nuclear membrane at prometaphase, and subsequently activates RhoA to stimulate cytokinesis [11, 18]. However, in non-small cell lung cancer (NSCLC) cells, ECT2 can also localize to the cytoplasm and affect tumor growth and invasion by forming a complex with $\mathrm{PKC}_{1}$-Par6a and activating Rac1 [19]. ECT2 is also regulated by posttranslational modifications, including phosphorylation and proteasome-dependent degradation [11, 20]. During mitosis, ECT2 is phosphorylated at two sites, Thr341 and Thr412, by cyclin-dependent kinase 1 (Cdk1), thus allowing regulation of ECT2 (GEF) activity and localization [21, 22]. In NSCLC, ECT2 is phosphorylated at Thr328 by $\mathrm{PKCl}$, which leads to activation of Rac1, thus driving malignant transformation [23].

Although cytoplasmic expression of ECT2 has been studied in lung cancer [19], details of its clinical significance and correlation with biological behavior are still limited. In the present study, we first examined the subcellular localization of ECT2 protein in lung adenocarcinoma cell lines.
We then investigated the correlation between cytoplasmic ECT2 expression and clinicopathological factors, as well as prognosis, using 167 cases of lung adenocarcinoma at different stages. Finally, we studied the correlation between the subcellular localization of ECT2 and its phosphorylation at T790 in lung adenocarcinoma cells.

\section{Materials and methods}

\section{Patients}

A total of 167 lung adenocarcinomas that had been surgically resected between 1998 and 2007 at the Department of Pathology, University of Tsukuba Hospital (Ibaraki, Japan), were examined for this study. There were 65 advanced adenocarcinomas $(>2 \mathrm{~cm}$ in diameter) and 102 small adenocarcinomas ( $\leq 2 \mathrm{~cm}$ in diameter) including 24 cases of AIS, 9 cases of MIA, and 69 cases of early but invasive adenocarcinoma. We also prepared scraping cytology specimens from the fresh cut surfaces of 13 lung adenocarcinomas $(>2 \mathrm{~cm}$ in diameter) resected at the University of Tsukuba Hospital (Ibaraki, Japan) and Ibaraki Higashi National Hospital (Ibaraki, Japan) for further investigation. Informed consent for study of all materials had been obtained from all of the patients. Pathological staging was based on the UICC TNM Classification of Malignant Tumors, 8th edition.

\section{Antibodies}

Primary antibodies used in this study for western blotting were those against ECT2 (1:500, Millipore, Billerica, MA, USA), P-ECT2 (T790) (1:500, Abcam, Cambridge, UK), MEK1/2 (1:500, Cell Signaling, Danvers, MA), PhosMEK1(Ser298) (1:500, Cell Signaling), ERK1,2 (1:500, Cell Signaling), Phos-ERK1,2 (1:500, Cell Signaling), lamin-B (C-20) (1:1000, Santa Cruz Biotechnology, Dallas, TX, USA), $\alpha$-tubulin (1:500, Wako, Osaka, Japan), sodium potassium ATPase [EP 1845Y] plasma membrane loading control (1:100 000, Abcam), and $\beta$-actin (1:5000, SigmaAldrich, St. Louis, MO). The secondary antibodies were Alexa fluor 555-conjugated anti-rabbit IgG (1:1000, Cell Signaling), polyclonal goat anti-rabbit immunoglobulin Horseradish Peroxidase (HRP) (Dako, Glostrup, Denmark), HRP-conjugated goat anti-mouse Fc IgG antibody (1:200,000, Abcam), and Clean-Blot ${ }^{\mathrm{TM}}$ IP Detection Reagent (HRP) (1:4000, Thermo Fisher Scientific, Waltham, MA).

\section{Cell lines and culture conditions}

The PC-9, A549, and RERF-LC-KJ cell lines were obtained from RIKEN Cell Bank (Ibaraki, Japan). The 
Calu-3, NCI-H1975, NCI-H1650, NCI-H2342, and NCI$\mathrm{H} 23$ cell lines were obtained from the American Type Culture Collection. The immortalized human lung cell line PL16B derived from bronchial epithelial cells was established in our laboratory [24]. The PC-9, NCI-H23, and RERF-LC-KJ cells were cultured in RPMI-1640 medium (Thermo Fisher Scientific) supplemented with $10 \%$ fetal bovine serum (FBS) (Sigma-Aldrich). Calu-3 cells were cultured in Eagle's Minimum Essential Medium (EMEM) with L-glutamine and phenol red (Wako) medium supplemented with $10 \%$ FBS. A549 cells were cultured in Dulbecco's modified Eagle's medium/F12 (DMEM/F12) (Thermo Fisher Scientific) supplemented with $10 \%$ FBS. NCI-H1975 and NCI-H1650 cells were cultured in RPMI-1640 medium (ATCC Modification) (Thermo Fisher Scientific) supplemented with $10 \%$ FBS. NCI-H2342 cells were culture in DMEM/F12 (Thermo Fisher Scientific) supplemented with 5\% FBS, $0.005 \mathrm{mg} /$ $\mathrm{ml}$ human insulin (Wako), $0.01 \mathrm{mg} / \mathrm{ml}$ transferrin (SigmaAldrich), $30 \mathrm{nM}$ sodium selenite (Sigma-Aldrich), $10 \mathrm{nM}$ hydrocortisone (Wako), $10 \mathrm{nM}$ beta-estradiol (SigmaAldrich), and extra $2 \mathrm{mM}$ L-glutamine (Sigma-Aldrich). PL16B cells were cultured in MCDB 153 HAS (Wako) medium supplemented with $2 \%$ FBS, $5 \mu \mathrm{g} / \mathrm{ml}$ human insulin (Wako), $10 \mu \mathrm{g} / \mathrm{ml}$ transferrin (SigmaAldrich), $20 \mathrm{ng} / \mathrm{ml}$ sodium selenite (Sigma-Aldrich), $72 \mathrm{ng} / \mathrm{ml}$ hydrocortisone (Wako), and $0.5 \mathrm{ng} / \mathrm{ml}$ EGF (Toyobo, Tokyo, Japan). All cells were incubated at $37{ }^{\circ} \mathrm{C}$ with $5 \% \mathrm{CO}_{2}$.

\section{Immunoblotting and immunoprecipitation}

For immunoblotting assay, we used cellular protein extracts from PL16B cells and eight lung adenocarcinomas cell lines (A549, NCI-H23, Calu-3, NCI-H1975, RERF-LC-KJ, PC-9, NCI-H1650, and NCI-H2342). The cells were washed with ice-cold phosphate-buffered saline (PBS), scraped from dishes, dissolved in cell lysis buffer using M-PER Mammalian Protein Extraction Reagent (Thermo Fisher Scientific) containing protease and phosphatase inhibitor cocktail (Thermo Fisher Scientific), incubated for $5 \mathrm{~min}$, and centrifuged for $10 \mathrm{~min}$ at $14,000 \times g$ at $4{ }^{\circ} \mathrm{C}$. The supernatant was transferred to new tubes, and protein levels were measured using BCA protein assay kits (Thermo Fisher Scientific). Equal amount of cell lysate $(20 \mu \mathrm{g})$ were mixed with $5 \times$ sample loading buffer supplemented with Dithiothreitol (DTT), followed by denaturation at $95{ }^{\circ} \mathrm{C}$ for $5 \mathrm{~min}$. Polypeptides were electrophoresed on Mini-PROTEAN TGX Precast Gels (Bio-Rad Laboratories, Hercules, CA) and transferred to polyvinylidene difluoride membranes using the iBlot $^{\mathrm{TM}}$ gel transfer system (Thermo Fisher Scientific). The membranes were incubated with each primary antibody overnight at $4{ }^{\circ} \mathrm{C}$, washed with PBS (Cell Signaling) containing $0.1 \%$ Tween-20, and incubated with an appropriate secondary antibody for $1 \mathrm{~h}$ at room temperature. After washing the blots extensively, proteins were visualized using SuperSignal West Femto Maximum sensitivity substrate (Thermo Fisher Scientific), and images were taken using a ChemiDoc ${ }^{\mathrm{TM}}$ Touch Imaging system (Bio-Rad Laboratories). ECT2 signals were detected at $104 \mathrm{kDa}$. All proteins extracted in this study were stored at $-80^{\circ} \mathrm{C}$ until required.

For the immunoprecipitation assay, PL16B, NCI-H23, and Calu-3 cells were washed with PBS, then lysed in Pierce IP Lysis Buffer (Thermo Fisher Scientific). Six hundred micrograms of whole-cell lysate from each cell line was incubated with anti-ECT2-antibody overnight at $4{ }^{\circ} \mathrm{C}$ on a rotator. Next, $100 \mu$ l of pre-cleaning protein A magnetic beads (Bio-Rad Laboratories) was added and incubated for $1 \mathrm{~h}$ at $4{ }^{\circ} \mathrm{C}$ on a rotator. After washing three times, protein A magnetic beads were captured using a magnetic stand. Bound proteins were separated from the beads by adding $5 \times$ sample loading buffer supplemented with DTT and boiling at $95^{\circ} \mathrm{C}$. Samples were subjected to sodium dodecyl sulfate-polyacrylamide gel electrophoresis, followed by immunoblotting assay. The experiments were replicated three independent times.

\section{RNA isolation and quantitative real-time PCR}

Total RNA was extracted from PL16B cells and the eight lung adenocarcinomas cell lines (A549, NCI-H23, Calu-3, NCI-H1975, RERF-LC-KJ, PC-9, NCI-H1650, and NCIH2342) using a RNeasy Mini Plus Kit (QIAGEN, Hilden, Germany) following the manufacturer's instructions. Complementary DNA (cDNA) was synthesized from total RNA $(1 \mu \mathrm{g})$ using a high-capacity cDNA Reverse Transcription Kit (Thermo Fisher Scientific). Quantitative RT-PCR was carried out with SYBR ${ }^{\circledR}$ Premix EX Taq ${ }^{\mathrm{TM}}$ (Perfect Real Time, Takara Bio, Shiga, Japan) on a GeneAmp ${ }^{\circledast}$ 7300 sequence detection system (Thermo Fisher Scientific) in accordance with the manufacturer's instructions. The $18 \mathrm{~S}$ ribosomal RNA gene was used for normalization. The following specific primer pair for ECT2 used for RT-PCR was purchased from Takara: sense, 5'-CAAATGGATGCCCG AGCTG-3'; antisense, 5'-ACGTCGTTTGCGATTGCTG TTA-3'.

\section{Quantitation of ECT2 DNA by RT-PCR}

Genomic DNA was extracted from PL16B cells and the eight lung adenocarcinoma cell lines using a QIAamp DNA mini kit (Qiagen) in accordance with the manufacturer's recommended protocol. Genomic DNA was used as a PCR template, and quantification of DNA copy number was 
carried out with SYBR $^{\circledR}$ Premix EX Taq ${ }^{\mathrm{TM}}$ (Perfect Real Time, Takara Bio) on a GeneAmp ${ }^{\circledR} 7300$ sequence detection system (Thermo Fisher Scientific) following the manufacturer's instructions. The specific primer pair for ECT2 was designed and used as described previously [10]. The primer sequences were: sense, 5'-GCAA ACCTGCCCTGAGAAAA-3'; antisense, 5'-CAAGGCCT GGACAAACCTGT- $3^{\prime}$. The GAPDH gene was used for normalization.

\section{Fluorescence in situ hybridization (FISH)}

Calu-3, NCI-H2342, NCI-H23, and RERF-LC-KJ cells were fixed with $10 \%$ neutral buffered formalin, and paraffin-embedded sections $5 \mu \mathrm{m}$ thick were prepared. The sections were deparaffinized and dehydrated, and then incubated with pretreatment solution for $30 \mathrm{~min}$ at $95^{\circ} \mathrm{C}$. After washing using $2 \times \mathrm{SSC}$ washing buffer, the sections were treated with protease solution for $15 \mathrm{~min}$ at $37^{\circ} \mathrm{C}$. After washing using $2 \times \mathrm{SSC}$ washing buffer, $10 \mu \mathrm{l}$ of DNA probe (ECT2/CEN3q Dual Color FISH Probe (GSP Lab., Kanagawa, Japan) was added, denatured for $5 \mathrm{~min}$ at $75^{\circ} \mathrm{C}$, and then hybridized for $72 \mathrm{~h}$ at $37^{\circ} \mathrm{C}$. Sections were stained with 4,6-diamidino-2-phenylindole (DAPI) and imaged using a fluorescence microscope (Biorevo BZ-9000; Keyence, Osaka, Japan). For evaluation, the signals of 100 randomly selected cells were counted.

\section{Cell proliferation assay}

Calu-3 and NCI-H23 cells were transfected with small interfering RNA (siRNA) against ECT2 or negative control scrambled RNA and seeded at density of $8 \times 10^{4}$ cells/ $\mathrm{ml}$. After $48 \mathrm{~h}$, cell proliferation was assessed using a cell counting kit-8 (DOJINDO, Kumamoto, Japan) in accordance with the manufacturer's protocol. Absorbance was measured at $450 \mathrm{~nm}$ using a Microplate Reader (Bio-Rad Laboratories). Data were representative of three independent experiments.

\section{Cell invasion and migration assays}

Calu-3 cells were transfected with siRNA against ECT2 or negative control scrambled RNA. Forty-eight hours after transfection, the cells were trypsinized and resuspended in FBS-free medium. Cell migration and invasion were assessed using CytoSelect 24-well Migration and Invasion Assays (Cell Biolabs, San Diego, CA) in accordance with the manufacturer's protocol.

Briefly, a total of $0.5 \times 10^{6}$ cells $/ \mathrm{ml}$ in serum-free medium were added to the top chamber of a transwell. Medium supplemented with $10 \%$ FBS was added to the bottom well. After $24 \mathrm{~h}$ of incubation at $37^{\circ} \mathrm{C}$, any non-migratory or non-invasive cells in the top chambers were removed. The migrated and invaded cells were stained with cell stain solution, lysed and measured at $560 \mathrm{~nm}$ using a Microplate Reader (Bio-Rad Laboratories). Data were representative of three independent experiments.

\section{Cell fractionation}

Nuclear and cytoplasmic fractions were extracted from five lung adenocarcinoma cell lines (Calu-3, A549, NCI-H2342, NCI-H23, and NCI-H1975) and from PL16B cells. The fractionations were performed using an NE-PER Nuclear Cytoplasmic Extraction Kit (Thermo Fisher Scientific) in accordance with the manufacturer's protocol. Six cell lines (Calu-3, A549, NCI-H2342, NCI-H23, NCI-H1975, and PL16B) showed a specific ECT2 signal in both the nuclear and cytoplasmic fractions at $104 \mathrm{kDa}$.

\section{Immunohistochemistry}

One hundred sixty-seven surgically resected lung adenocarcinomas were fixed with $10 \%$ neutral buffered formalin, and then embedded in paraffin. Three-micrometer-thick sections were cut, deparaffinized, and dehydrated. Antigen retrieval was performed by autoclaving in $10 \mathrm{mM}$ Tris- $\mathrm{HCl}$ $1 \mathrm{mM}$ EDTA (1× Tris-EDTA, pH 8; TE buffer) for $15 \mathrm{~min}$ at $105^{\circ} \mathrm{C}$. Endogenous peroxidase was then blocked using $\mathrm{H}_{2} \mathrm{O}_{2}$ for $5 \mathrm{~min}$, followed by incubation with the primary antibody specific for ECT2 (1:200 dilution) for 30 min. The sections were then incubated with REAL Envision HRP rabbit/mouse (EnVision DualLink; Dako) for $30 \mathrm{~min}$, and the reaction products were detected using DAB (Dako REAL Envision Detection System; Agilent Technologies) in accordance with the manufacturer's instructions. Immunohistochemical staining was performed using a Nichirei Histostainer 36A (Nichirei Bioscience, Tokyo, Japan). Nuclei were stained with hematoxylin for $15 \mathrm{~s}$.

\section{Antibody validation}

To confirm the specificity of P-ECT2(T790) staining, lambda phosphatase (New England Biolabs; Ipswich, MA) was applied to the slides before incubation with the primary antibody in accordance with a previous study [25]. Briefly, after blocking of endogenous peroxidase activity with $\mathrm{H}_{2} \mathrm{O}_{2}$ for $5 \mathrm{~min}$, the slides were washed with distilled water and incubated with lambda phosphatase at $10,000 \mathrm{U} / \mathrm{ml}$ in reaction buffer containing $\mathrm{MnCl}_{2}$ at $37^{\circ} \mathrm{C}$ for $1 \mathrm{~h}$. The control slides were incubated separately with reaction buffer only. The slides were washed with distilled water several times, and then subjected to the immunohistochemistry protocol described above. 


\section{Immunocytochemistry}

Three cell lines (PL16B, NCI-H23, and Calu-3) and 13 scraping cytology specimens from freshly resected cases of lung adenocarcinoma ( $>2 \mathrm{~cm}$ in diameter) were fixed with $10 \%$ formalin for $1 \mathrm{~h}$, and then subjected to the immunohistochemistry protocol described above.

Anti-P-ECT2 (T790) antibody at 1:80 dilution and antiECT2 antibody at 1:200 dilution were used as the primary antibodies and applied for $30 \mathrm{~min}$.

\section{Evaluation of immunostaining}

For ECT2 immunohistochemistry, 1000 tumor cells were evaluated for the most intense cytoplasmic staining (hot spot) in accordance with previous studies $[10,26]$, with minor modification. The cytoplasmic ECT2 immunohistochemistry score for the 167 surgically resected lung adenocarcinomas was determined by counting the number of cells showing cytoplasmic staining among 1000 tumor cells in each case. Normal alveolar epithelial cells were used as a negative control for ECT2 staining. Receiver Operating Characteristic (ROC) curve analysis was done to determine the best cut-off points at a coordinate of 10 for both disease-free survival (DFS) and overall survival (OS) (sensitivity 0.778 and 0.393 (1-specificity) and sensitivity 0.755 and 0.377 (1-specificity)), respectively. This coordinate of 10 was the closest to the upper left corner. Any scores below 10 were considered to indicate negativity for cytoplasmic ECT2 expression and the presence of only nuclear staining or negative staining, whereas scores of 10 or more were considered to indicate positive cytoplasmic expression of ECT2 (Supplementary Fig. 1).

We also counted the nuclear staining of ECT2 according to the same cut-off point at a coordinate of 10. The total ECT2 immunohistochemistry score for the 167 cases was determined by counting the number of cells showing the nuclear staining, as well as mixed cytoplasmic/nuclear staining among 1000 tumor cells in each case. The cut-off used to define the positive expression of ECT2 was $\geq 10$.

Thirteen scraping cytology specimens from freshly resected lung adenocarcinomas cases were evaluated and scored for their cytoplasmic expression of ECT2 and the expression of P-ECT2 (T790) using the protocol described above. Staining of P-ECT2 (T790) was located in the cytoplasm, as well as some membranes. The cut-off used to define cytoplasmic ECT2 and P-ECT2 (T790) positivity was $\geq 10$.

\section{Immunofluorescence}

Three cell lines (NCI-H23, Calu-3, and PL16B) were cultured on collagen-coated coverslips (Iwaki Biosciences, Tokyo,
Japan). After $24 \mathrm{~h}$, the cells were fixed in methanol for $10 \mathrm{~min}$, washed three times with PBS, and then incubated with Tris-buffered saline (TBS) for $30 \mathrm{~min}$. The cells were then reacted with the primary (anti-ECT2) antibody at 1:200 for $1 \mathrm{~h}$ at room temperature, and washed with PBS three times. They were then reacted with Alexa fluor 555conjugated anti-rabbit $\operatorname{IgG}$ for $1 \mathrm{~h}$ at room temperature. After rinsing again with PBS three times, the slides were mounted using VECTASHIELD ${ }^{\circ}$ HardSet Mounting Medium with DAPI (Vector Laboratories Inc., Burlingame, CA) and imaged using a fluorescence microscope (Biorevo BZ-9000).

\section{ECT2 knockdown with siRNA}

Calu-3 and NCI-H23 cells were cultured up to $80 \%$ confluence and then subjected to transfection using a specific siRNA against ECT2 with Lipofectamine RNAiMAX (Thermo Fisher Scientific) in OPTI-MEM reduced serum medium (Thermo Fisher Scientific) for $20 \mathrm{~min}$ at room temperature. The Lipofectamine complex was transferred to $2.5 \mathrm{ml}$ of medium containing $2 \times 10^{5}$ cells and in each well of a six-well plate. Equivalent numbers of Calu- 3 and NCI-H23 cells were also transfected with scrambled RNA (Stealth RNAi Negative Control Medium GC; Thermo Fisher Scientific) as a negative control. Knockdown efficiency was assessed by western blotting and RT-PCR at $48 \mathrm{~h}$ after transfection. The specific siRNA against ECT2 purchased from Thermo Fisher Scientific had the following sequences: sense, 5'-CAGAUAUCUUUGAUG UACACACUAA-3'; antisense, 5'-UUAGUGUGUAC AUCAAAGAUAUCUG-3'. Western blot analysis, immunohistochemistry, immunocytochemistry, and immunofluorescence staining were performed using the same antibodies.

\section{Statistical analysis}

Correlations between cytoplasmic ECT2 expression and clinicopathological factors in patients with lung adenocarcinoma were analyzed by chi-squared test. DFS and OS curves were assessed using the Kaplan-Meier method, and the significance of differences demonstrated by survival analysis was examined using log-rank test. Univariate and multivariate analyses were conducted using the Cox proportional hazards model. ROC curves were used to determine the best cut-off points. The statistical analyses were carried out using SPSS version 24 (SPSS, Chicago, IL). The correlation between the relative mRNA expression level and the relative copy number was determined using Pearson's test. Two-tailed Student's $t$-test and one-way analysis of variance (ANOVA) followed by a post hoc Tukey's honestly significant difference (HSD) test were 
a
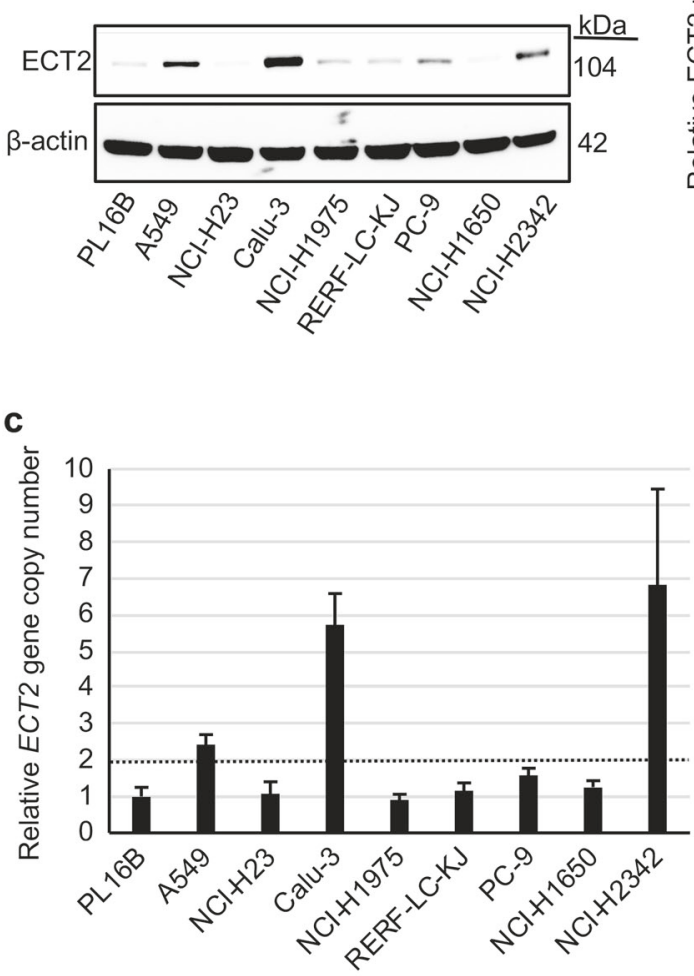

b

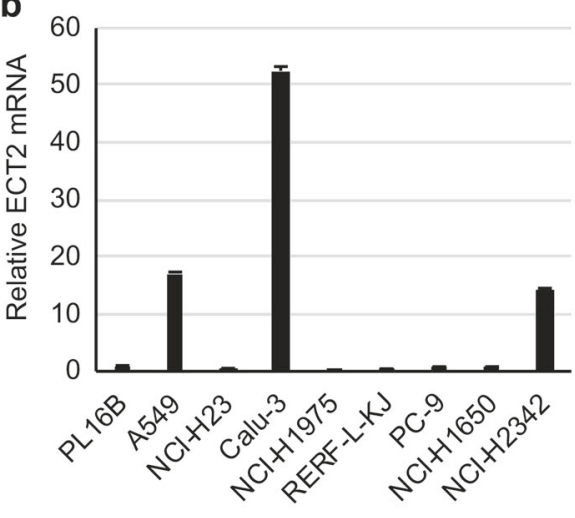

d

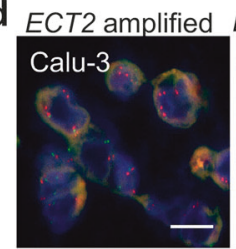

$\mathrm{NCl}-\mathrm{H} 2342$
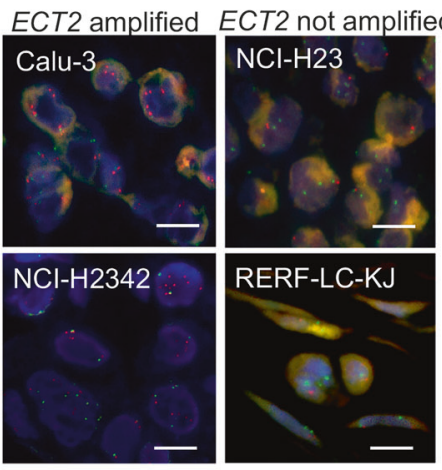

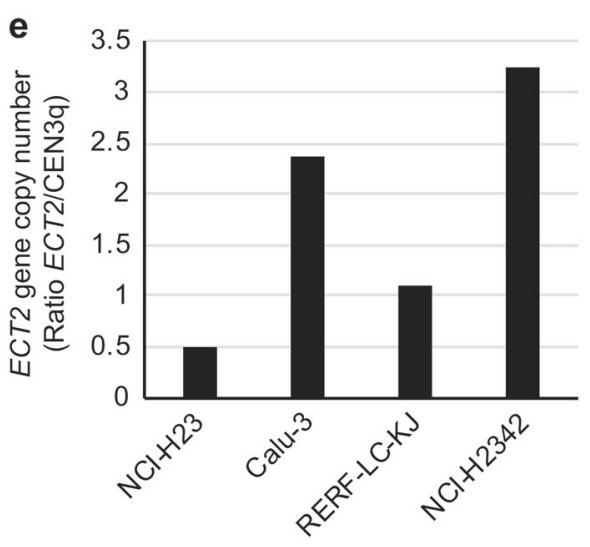

Fig. 1 ECT2 expression and amplification in lung adenocarcinoma cell lines. a Expression of ECT2 protein was examined by western blotting in PL16B cells and eight lung adenocarcinomas cell lines (A549, NCIH23, Calu-3, NCI-H1975, RERF-LC-KJ, PC-9, NCI-H1650, and NCI$\mathrm{H} 2342$ ). Equal amounts of lysate from the cell lines were probed using anti-ECT2 antibody; $\beta$-actin was used as a loading control. b Relative expression level of ECT2 mRNA from the same cell lines was analyzed by RT-PCR. ECT2 mRNA expression was normalized to the $18 \mathrm{~S}$ ribosomal RNA. Error bars represent mean $\pm \mathrm{SD}, n=3$. c Relative copy number of the ECT2 gene determined by RT-PCR in PL16B cells and eight lung adenocarcinoma cell lines. The ECT2 gene was normalized to the GAPDH gene. DNA levels in PL16B cells were considered equivalent to a value of 1 . The cut-off for twofold expression of the gene copy number is indicated by a dotted line. More than two

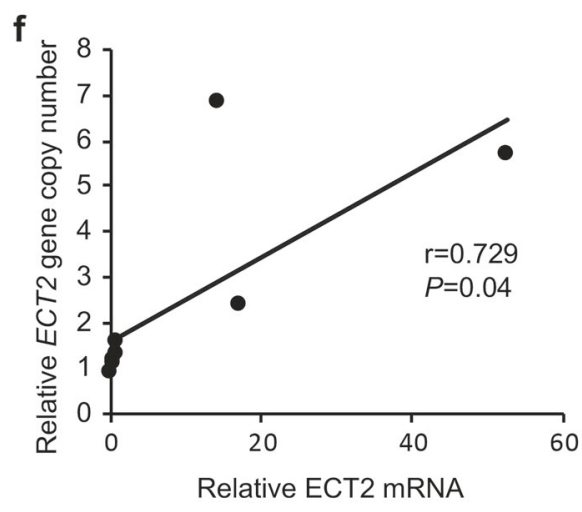

copies were defined as ECT2 amplification. Error bars represent mean $\pm \mathrm{SD}, n=3$. d Calu-3, NCI-H2342, NCI-H23, and RERF-LC-KJ cell lines examined by fluorescence in situ hybridization (FISH) with an ECT2 target red probe signal and a chromosome 3 centromere green probe signal (CEN3q). The nuclei were stained with DAPI. $\times 1000$ magnification, scale bar, $10 \mu \mathrm{m}$. e Quantitative FISH analysis of Calu3, NCI-H2342, NCI-H23, and RERF-LC-KJ cells using the probe for ECT2, and CEN3q as a control. The ECT2/CEN3q ratio in 100 randomly selected cells was counted for each cell line. Calu-3 and NCI$\mathrm{H} 2342$ cells showed ECT2 amplification with $>2$ copies of the ECT2 gene per cell. f Significant correlation (Pearson's correlation test, $r=$ $0.729 ; P=0.04)$ between the relative expression level of ECT2 mRNA and relative copy number was observed in eight lung adenocarcinoma cell lines 
Fig. 2 Knockdown of ECT2 inhibits cell growth, migration, invasion, and the MAPK signaling pathway in lung adenocarcinoma cells. a Western blot of ECT2 protein expression in Calu-3 and NCI-H23 cells transfected with siRNA against ECT2 or negative control (siCON) for $48 \mathrm{~h}$. b Suppression of ECT2 inhibited cell growth, *significantly different from siCON at (both $P<0.0001$ ) (Student's $t$-test), error bars represent mean $\pm \mathrm{SD}, n=3$, (c) migration and invasion, *significantly different from siCON at $(P<0.003, P<$ 0.0003 ) (Student's $t$-test), respectively. Error bars represent mean $\pm \mathrm{SD}, n=3$. $\times 400$ magnification, scale bar, $10 \mu \mathrm{m}$. d Effect of suppression ECT2 on the MAPK signaling pathway. e For western blot quantitative analysis, band density ratios of Phos-298-Mek1 to total Mek1,2, and f PhosErk1,2 to total Erk1,2 were analyzed and presented as mean $\pm \mathrm{SD}, n=4$. * Significantly different from siCON at $(P<$ $0.0003, P<0.005$ ) (Student's $t$-test), respectively a

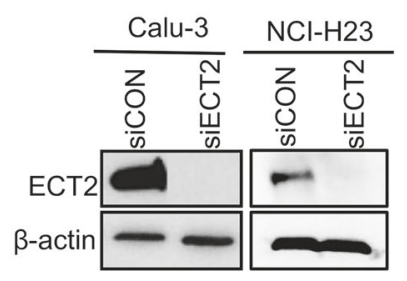

C
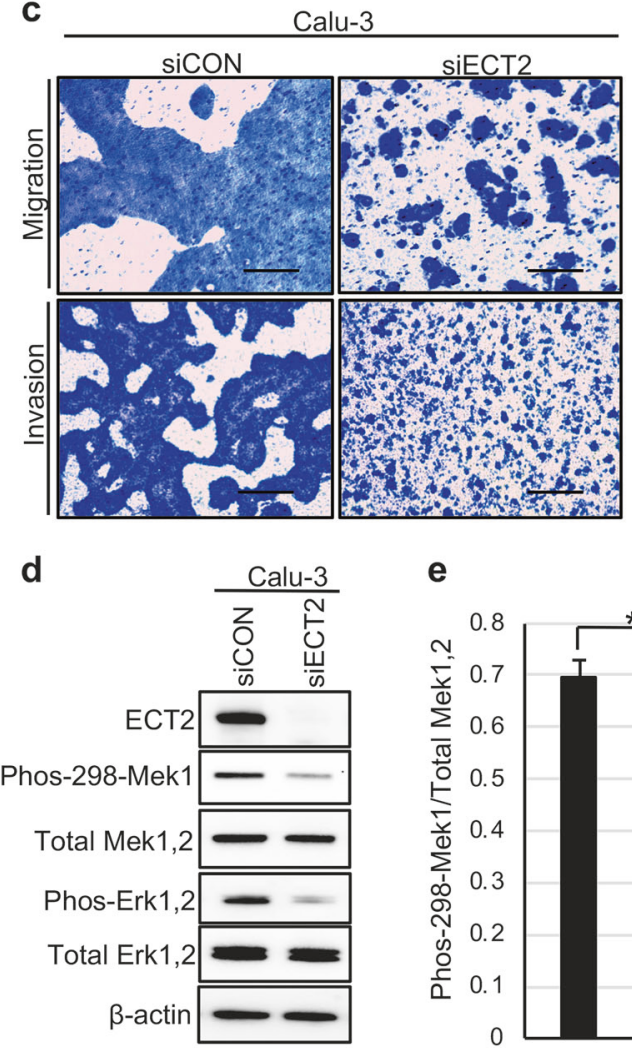

e
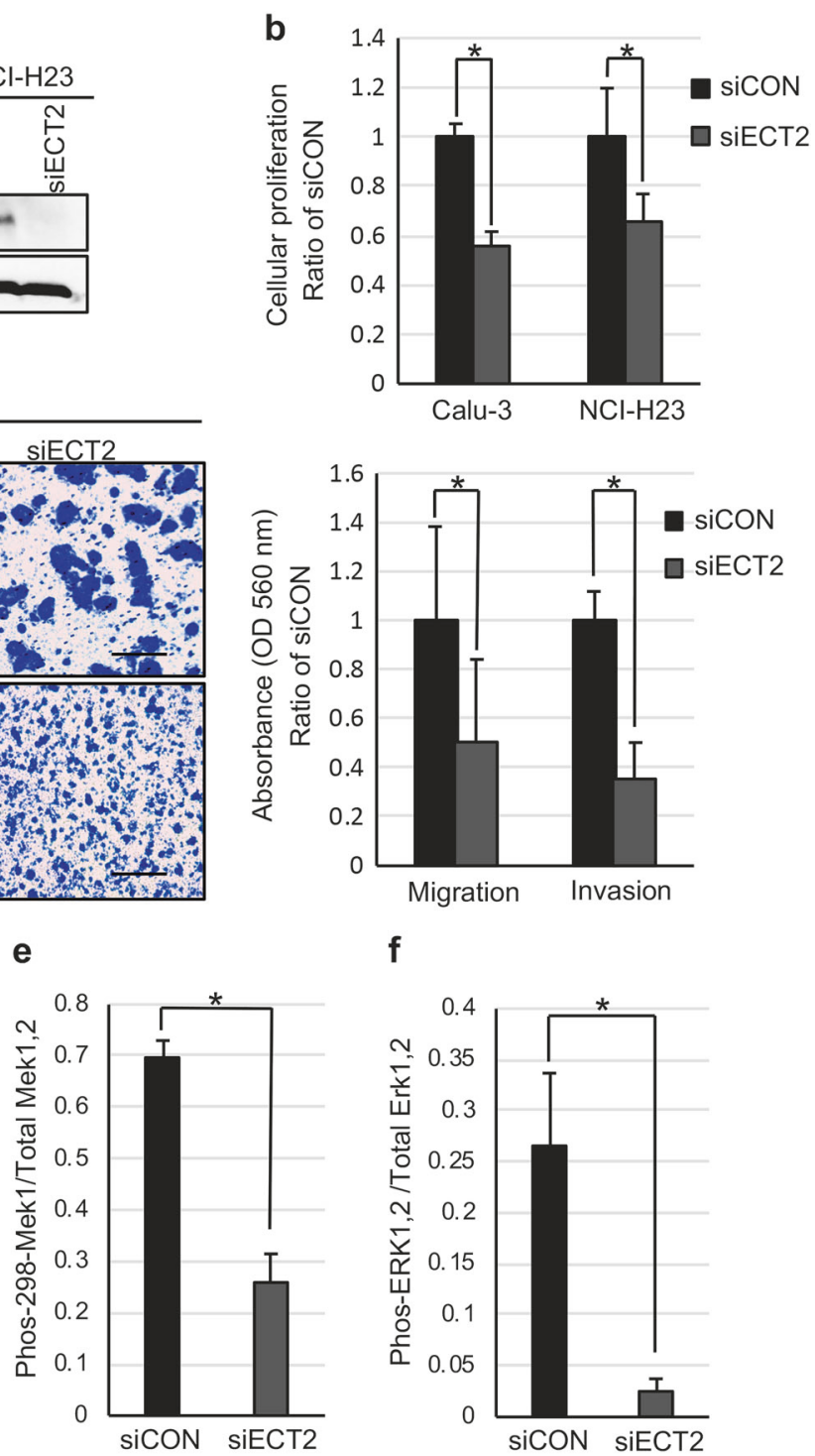

f

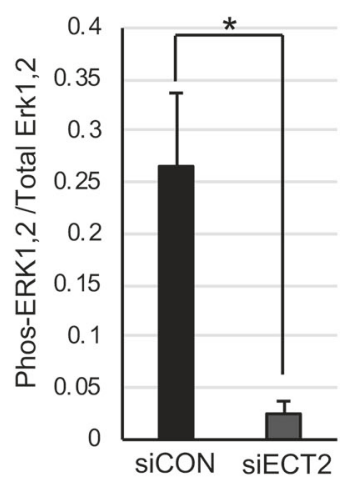

used to determine the significance of differences between groups. The significance level for statistical analysis was defined as $P<0.05$. Quantification of the western blots was determined by densitometry using ImageJ software (NIH, USA).

\section{Results}

\section{Expression of ECT2 in lung adenocarcinoma cell lines}

We first examined the expression of ECT2 in immortalized normal bronchial epithelium PL16B cells and eight lung adenocarcinoma cell lines (A549, NCI-H23, Calu-3, NCI-H1975, RERF-LC-KJ， PC-9， NCI-H1650， and NCI-H2342). As shown in Figs. 1a, b, western blotting and quantitative RT-PCR demonstrated that ECT2 was expressed in PL16B cells and all of the eight lung adenocarcinoma cell lines to various degrees. However, the levels of ECT2 protein and mRNA were higher in Calu-3, A549, and NCI-H2342 cells than in PL16B cells.

\section{Amplification of the ECT2 gene in lung adenocarcinoma cell lines}

Our previous study had shown that ECT2 was amplified in early invasive lung adenocarcinoma tissues [10]. In the present study, we examined amplification of the ECT2 gene in eight lung adenocarcinoma cell lines, and quantitative PCR revealed ECT2 gene amplification in three of them (A549, Calu-3, and NCIH2342). The twofold gene copy number cut-off, as 


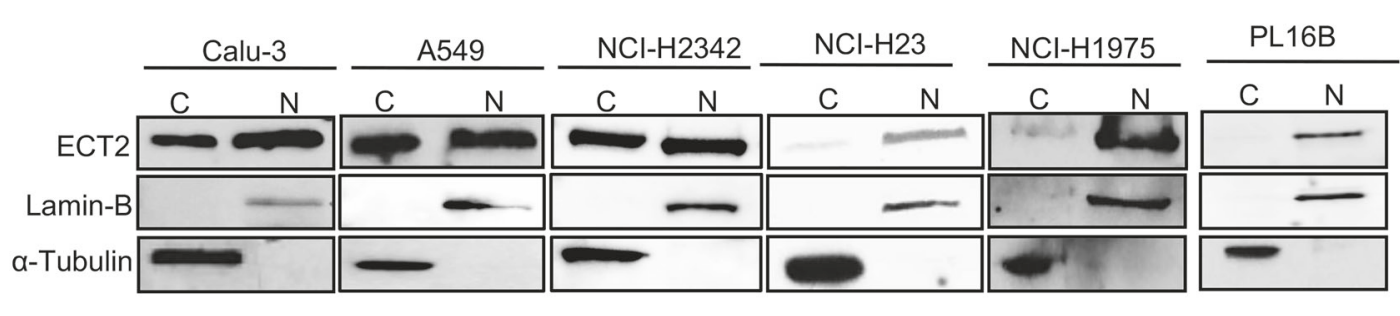

b
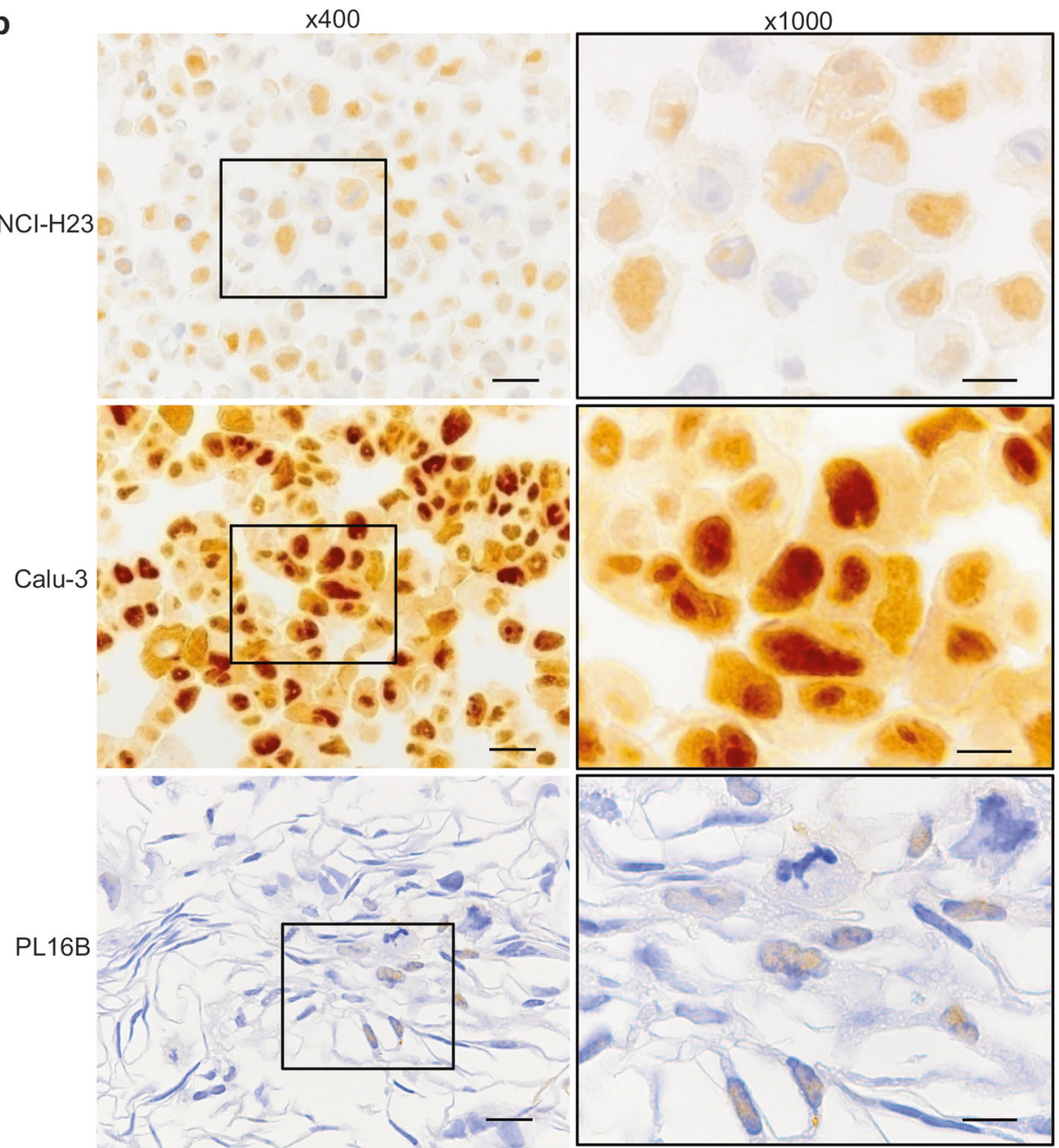

Fig. 3 Subcellular localization of ECT2 in lung adenocarcinoma cell lines. a Western blot analysis of cytoplasmic (C) and nuclear (N) fractions from five lung adenocarcinoma cell lines (Calu-3, A549, NCI-H2342, NCI-H23, and NCI-H1975), and PL16B cells. Lamin-B and $\alpha$-tubulin were used as controls for the nuclear and cytoplasmic

fractions, respectively. b Immunocytochemical images of three cell lines (NCI-H23, Calu-3, and PL16B) that were fixed with 10\% neutral buffered formalin and treated with anti-ECT2 antibody. $\times 400$ magnification, scale bar, $20 \mu \mathrm{m} . \times 1000$ magnification, scale bar, $10 \mu \mathrm{m}$

measured by quantitative PCR, demonstrated a clear distinction between lung adenocarcinoma cells and normal genomic DNA from PL16B cells (Fig. 1c). In order to confirm the difference in ECT2 gene copy number, FISH analysis was performed on the Calu-3, NCI-H2342, NCI$\mathrm{H} 23$, and RERF-LC-KJ cell lines. This revealed that ECT2 gene was amplified in Calu-3 and NCI-H2342, whereas no amplification was found in NCI-H23 and RERF-LC-KJ (Figs. 1d, e). These results (Figs. 1a-e) suggested that overexpression of ECT2 was associated with an alteration in its copy number. Significant correlation between ECT2 overexpression and amplification was observed (Fig. 1f, $r=0.729$; $P=0.04)$. 


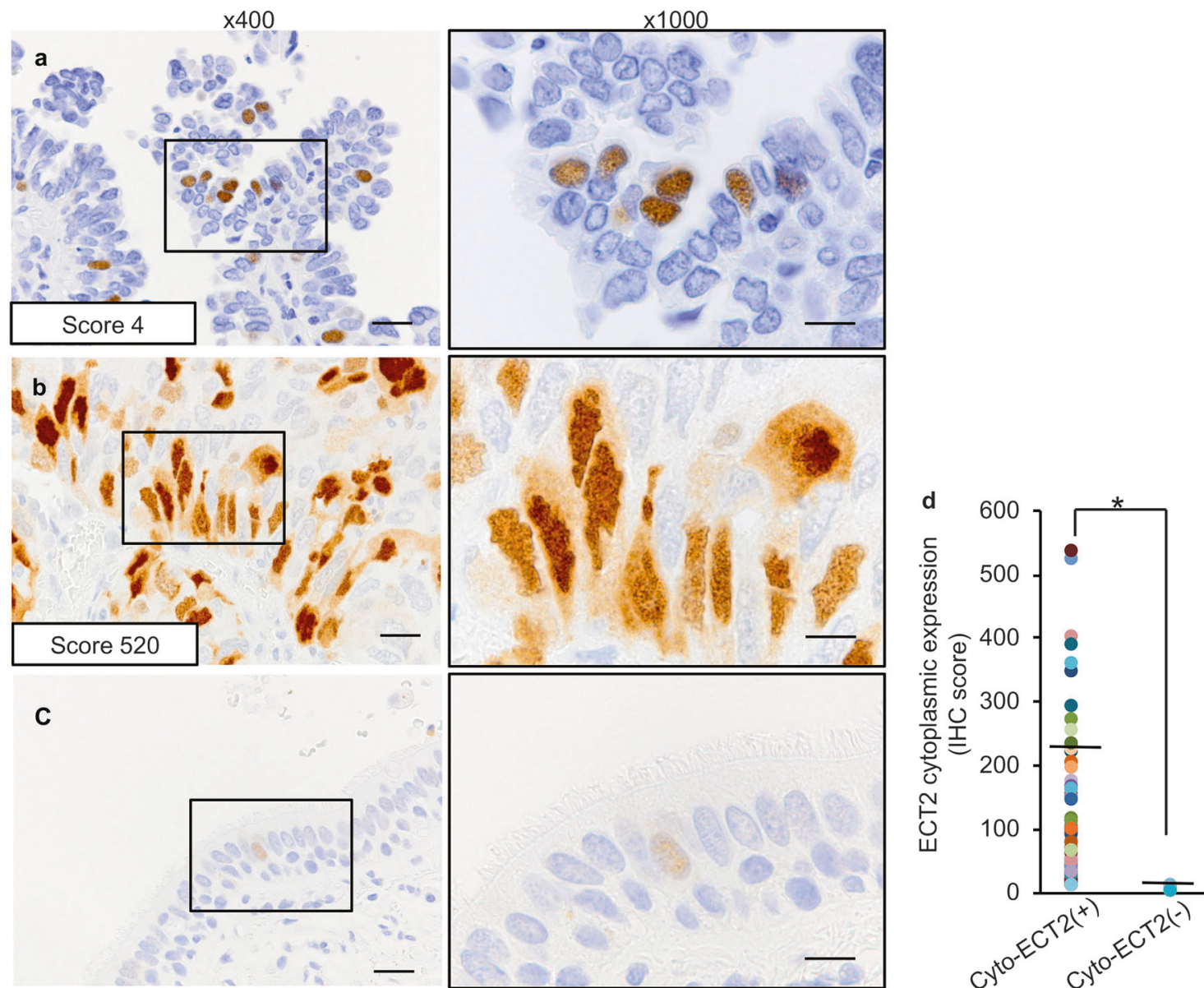

Fig. 4 Representative patterns of ECT2 expression in lung adenocarcinoma tissues, and normal bronchial epithelial cells. Immunohistochemical staining of ECT2 in lung adenocarcinoma tissues: Images a show ECT2 is localized mainly to the nucleus with a score of $4, \mathbf{b}$ the nucleus and cytoplasm with a score of 520, and $\mathbf{c}$ the nucleus of normal bronchial epithelial cells. $\times 400$ magnification, scale bar, $20 \mu \mathrm{m}$. $\times 1000$ magnification, scale bar, $10 \mu \mathrm{m}$. d Dot plot shows immunohistochemical score (IHC score) for cytoplasmic ECT2 expression in

\section{Inhibition of ECT2 suppresses the cell growth, migration, invasion, and MAPK signaling pathway of lung adenocarcinoma cells}

We tested the effect of ECT2 on cell viability, as shown in Figs. 2a, b. The growth of lung adenocarcinoma cells (Calu3 and NCI-H23) transfected with siECT2 was significantly lower than that of control cells (both $P<0.0001$ ). Transwell migration and invasion experiments showed that the motility and invasiveness of cells transfected with siECT2 were significantly lower than those of control cells $(P<0.003$, $P<0.0003$ ), respectively (Fig. 2c). Furthermore, the ratios of Phos-298-Mek1 and Phos-Erk1,2 were significantly lower in siECT2-treated cells than in control cells $(P<0.0003, P<$ 0.005), respectively (Figs. 2d-f). Taken together, these results suggested that ECT2 was sufficient and necessary for promotion of cell growth, motility, invasiveness, and the
167 cases of lung adenocarcinoma. Each dot represents an immunohistochemical score of cytoplasmic ECT2 from one individual case and horizontal lines indicate the average for each study group. The cutoff used to define cytoplasmic ECT2 positivity was $\geq 10$, as described in Materials and methods section. The difference between these scores for the cytoplasmic ECT2-positive (Cyto-ECT2(+)) and negative (Cyto-ECT2(-)) groups was statistically significant $(*) P<0.0001$

Mitogen-Activated Protein Kinase (MAPK) signaling pathway of lung adenocarcinoma cells.

\section{Subcellular localization of ECT2 protein in lung adenocarcinoma cell lines}

We examined whether ECT2 overexpression and amplification reflected changes in its subcellular localization. We selected Calu-3, A549, and NCI-H2342 cells in view of their overexpression and amplification of ECT2, and NCI-H23 and NCI-H1975 cells in view of their weak expression and lack of gene amplification. Western blotting analysis of the fractionated cell lysate revealed ECT2 protein in both the nuclear and cytoplasmic fractions of all five lung adenocarcinomas cell lines (Fig. 3a). However, the level of aberrant cytoplasmic ECT2 protein was higher in Calu-3, A549, and NCI-H2342 than in NCI-H23 and NCI-H1975. In addition, PL16B cells 
Table 1 Cytoplasmic localization of ECT2 in relation to the histology of lung adenocarcinoma

\begin{tabular}{llll}
\hline $\begin{array}{l}\text { Histological } \\
\text { classification }\end{array}$ & $\begin{array}{l}\text { No. of } \\
\text { cases }\end{array}$ & $\begin{array}{l}\text { Cytoplasm }(-) \\
(\%)\end{array}$ & $\begin{array}{l}\text { Cytoplasm }(+) \\
(\%)^{\mathrm{a}}\end{array}$ \\
\hline $\begin{array}{l}\leq 2 \mathrm{~cm} \text { (Small } \\
\text { adenocarcinomas) }\end{array}$ & 102 & & \\
$\quad$ AIS & 24 & $24(100)$ & $0(0)$ \\
$\quad$ MIA & 9 & $8(89)$ & $1(11)$ \\
$\quad \begin{array}{l}\text { Invasive } \\
\text { adenocarcinomas }\end{array}$ & 69 & $40(58)$ & $29(42)$ \\
$>2$ cm (Advanced & 65 & $12(18)$ & $53(82)$ \\
adenocarcinomas) & & &
\end{tabular}

AIS adenocarcinoma in situ, MIA minimally invasive adenocarcinoma ${ }^{a}$ Chi-squared test was used for comparison between two groups ( $\leq 2 \mathrm{~cm}$ and $>2 \mathrm{~cm}$ adenocarcinoma), $P<0.001$

showed predominant nuclear localization of ECT2 protein (Fig. 3a). Immunocytochemical and immunofluorescence staining confirmed the variations in ECT2 subcellular localization in NCI-H23, Calu-3, and PL16B cells (Fig. 3b and Supplementary Fig. 2).

\section{Aberrant cytoplasmic localization of ECT2 in early invasive adenocarcinoma}

To determine whether cytoplasmic expression of ECT2 changes during progression of lung adenocarcinoma, we examined 167 cases of lung adenocarcinoma using immunohistochemistry. Figures $4 \mathrm{a}, \mathrm{b}$ show two representative cases; one expressed ECT2 protein only in the nucleus, and the other showed both nuclear and cytoplasmic expression. In addition, nuclear localization of ECT2 protein was detected in some of the normal bronchial epithelial cells (Fig. 4c). We further examined the correlation between ECT2 expression and localization in 167 cases. The results showed that the mean \pm SD scores for the cytoplasmic ECT2-positive and negative groups were $117.2 \pm 132.87$ and $2.08 \pm 2.11$, respectively. The difference between these scores for the two groups was statistically significant $(P<0.0001)$ (Fig. 4d). Although all of the cases with cytoplasmic staining also showed positivity in the nucleus, the cases negative for cytoplasmic staining included those that did and did not show nuclear positivity. As Table 1 shows, among the small adenocarcinomas ( $\leq 2 \mathrm{~cm}$ in diameter), cytoplasmic positivity for ECT2 was observed in 1 (11\%) MIA, and 29 (42\%) invasive adenocarcinomas. On the other hand, among the advanced adenocarcinomas ( $>2 \mathrm{~cm}$ in diameter), we observed cytoplasmic positivity for ECT2 in $53(82 \%)$. Therefore, most of the AIS and MIA cases $32(97 \%)$ showed nucleus ( + or $-)$ /cytoplasm (-), whereas $40(58 \%)$ of the invasive adenocarcinomas ( $\leq 2 \mathrm{~cm}$ in diameter) and only $12(18 \%)$ of
Table 2 Correlation between cytoplasmic ECT2 expression and clinicopathological factors in patients with lung adenocarcinoma

\begin{tabular}{|c|c|c|c|}
\hline $\begin{array}{l}\text { Clinicopathological } \\
\text { factors }\end{array}$ & Cytoplasm (-) & Cytoplasm (+) & $P$-value \\
\hline Patients & 84 & 83 & \\
\hline Age (years) & & & 0.175 \\
\hline$\leq 60$ & 19 & 12 & \\
\hline$>60$ & 65 & 71 & \\
\hline Gender & & & $<0.001$ \\
\hline Male & 25 & 63 & \\
\hline Female & 59 & 20 & \\
\hline Lymph node metastasis & & & 0.003 \\
\hline NO/Nx & 76 & 60 & \\
\hline $\mathrm{N} 1 / \mathrm{N} 2$ & 8 & 23 & \\
\hline Distant metastasis & & & 0.079 \\
\hline $\mathrm{M} 0 / \mathrm{Mx}$ & 84 & 80 & \\
\hline M1 & 0 & 3 & \\
\hline Pathological stage $^{\mathrm{a}}$ & & & $<0.001$ \\
\hline pStage 0 & 24 & 0 & \\
\hline pStage I & 51 & 50 & \\
\hline pStage II & 3 & 16 & \\
\hline pStage III & 6 & 16 & \\
\hline pStage IV & 0 & 1 & \\
\hline Pleural invasion & & & $<0.001$ \\
\hline pl0 & 76 & 46 & \\
\hline pl1-3 & 8 & 37 & \\
\hline Vascular invasion & & & $<0.001$ \\
\hline Negative & 76 & 35 & \\
\hline Positive & 8 & 48 & \\
\hline Lymphatic permeation & & & $<0.001$ \\
\hline Negative & 69 & 38 & \\
\hline Positive & 15 & 45 & \\
\hline
\end{tabular}

Clinicopathological factors were analyzed using chi-squared test. Bold font indicates statistical significance

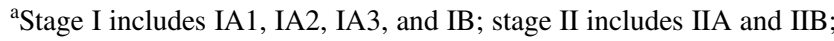
stage III includes IIIA, IIIB, and IIIC; stage IV includes IVA

advanced adenocarcinomas ( $>2 \mathrm{~cm}$ in diameter) did so. We counted tumors that showed cytoplasmic expression of ECT2 regardless of nuclear staining as an independent variable. The cut-off used to define cytoplasmic ECT2 positivity was $\geq 10$, as described in Materials and methods section. These findings suggested that cytoplasmic ECT2 expression increased progressively from non-invasive to early invasive and invasive adenocarcinoma $(P<0.001)$.

\section{Association between cytoplasmic ECT2 expression and clinicopathological parameters}

We examined the association between cytoplasmic ECT2 expression and clinicopathological factors in 167 cases of lung adenocarcinomas using chi-squared test. As shown in Table 2, 
among the 167 cases, 83 (50\%) showed cytoplasmic ECT2 staining. Positive cytoplasmic expression of ECT2 was significantly correlated with gender $(P<0.001)$, lymph node metastasis $(P=0.003)$, pathological stage $(P<0.001)$, pleural invasion $(P<0.001)$, vascular invasion $(P<0.001)$, and lymphatic permeation $(P<0.001)$. However, no significant correlation was observed between cytoplasmic ECT2 expression and other clinical parameters such as age and distant metastasis.

\section{Correlation between cytoplasmic ECT2 expression and prognosis}

We evaluated the clinical outcomes of the 167 patients with lung adenocarcinoma in relation to cytoplasmic expression of ECT2 using Kaplan-Meier analysis and log-rank test. The results showed that patients whose tumors expressed ECT2 in the cytoplasm had a significantly poorer outcome in terms of both DFS $(P<$ $0.001)$ and OS $(P<0.001)$ than those whose tumors lacked cytoplasmic ECT2 (Figs. 5a, b). Such a relationship between the prognosis and ECT2 localization was also found within subgroups of patients at early stages ( 0 and I) (both DSF and OS $P<0.001$ ) (Figs. 5c, d). However, for those at advanced stages (II, III, and IV) the survival analysis showed no differences between cytoplasmic ECT2-positive and negative groups (DSF $P=$ 0.768 , OS $P=0.463$ ) (Figs. 5e, f). To clarify whether the survival curves of the cytoplasmic ECT2-positive and -negative groups are driving by gender differences, we examined the outcome in males and females separately in relation to cytoplasmic expression of ECT2. We found that males and females showed no differences in outcome, and their survival curves indicated that cytoplasmic ECT2 positivity was significantly correlated with shorter DSF and OS than cytoplasmic ECT2 negativity (Supplementary Fig. 3), suggesting that cytoplasmic ECT2 expression could affect the prognosis regardless of gender in patients with lung adenocarcinoma. We also examined the correlation between ECT2(+) (both the nuclear and mixed cytoplasmic/nuclear staining) and the survival of lung adenocarcinoma patients. The results showed that the positive expression of ECT2 was significantly associated with poor survival in terms of both DFS and OS (both $P<$ 0.001) (Supplementary Fig. 4).

Furthermore, multivariate regression analyses based on the Cox proportional hazard model showed that the level of cytoplasmic ECT2 expression $(P=0.025)$, and the presence of lymphatic permeation $(P=0.013)$, were independent factors that affected OS (Table 3) but not DFS (data not shown). These results suggested that cytoplasmic expression of ECT2 might be of potential value as an independent marker for prediction of poor outcome in patients with lung adenocarcinoma.

\section{ECT2 phosphorylation at T790 correlates with cytoplasmic localization}

A previous study has demonstrated that the phosphorylated form of ECT2 interacts with the cytoplasmic signaling pathway to drive cellular transformation [23]. Therefore, we evaluated the expression of ECT2 phosphorylated at Thr790 (P-ECT2(T790)). First, we examined the specificity of an antibody that reacted specifically with phosphorylated ECT2 at T790. After transfection of ECT2 siRNA into Calu-3 cells, western blot analysis revealed that suppression of ECT2 reduced the level of P-ECT2(T790) expression, suggesting that this antibody specifically recognized ECT2 phosphorylated at T790 (Fig. 6a). Suppression of ECT2 expression by the ECT2 siRNA was confirmed by western blotting and quantitative RT-PCR (Figs. 6a, b). In addition, we further confirmed the staining specificity of the P-ECT2 (T790) antibody by treating Calu-3 cells with lambda phosphatase before applying the primary antibody, and this was sufficient to remove staining for P-ECT2(T790) in the cytoplasm and membrane of the cells (Supplementary Fig. 5).

In order to determine the levels of P-ECT2(T790) expression in lung adenocarcinoma cells, immunoprecipitation of ECT2 was performed using equal amounts of total cell lysates from PL16B, NCI-H23, and Calu-3 cells. As shown in Figs. 6c, d, expression of P-ECT2(T790) was significantly higher in Calu-3 than in PL16B and NCI-H23 cells.

We then investigated the localization of P-ECT2(T790) in Calu-3 and PL16B cells by immunocytochemistry with the anti-P-ECT2(T790) antibody. Interestingly, immunocytochemical staining for P-ECT2(T790) was detected mainly in the cytoplasm with some membranes staining of Calu-3 cells, whereas PL16B cells were negative for PECT2(T790) (Fig. 6e). We also found that ECT2 protein was distributed to the cell membrane of Calu-3 and A549 cells (Supplementary Fig. 6). To further study the correlation between P-ECT2(T790) expression and ECT2 subcellular localization in lung adenocarcinoma cells, we examined 13 scraping cytology specimens from freshly resected cases of lung adenocarcinoma using immunocytochemistry. P-ECT2(T790) positivity was located mainly in the cytoplasm along with some membrane staining. Interestingly, nuclear staining of P-ECT2(T790) was negative or very weak (Fig. 7b). Additionally, the expression of P-ECT2(T790) was correlated with cytoplasmic localization of ECT2 (Table 4). In six cases, it was noteworthy that when ECT2 was localized to both the nucleus and the cytoplasm, P-ECT2(T790) was more commonly expressed in the cytoplasm with some membranes staining (Figs. 7a, b, and Table 4). However, in seven cases where ECT2 expression was localized mainly in the nucleus, the 

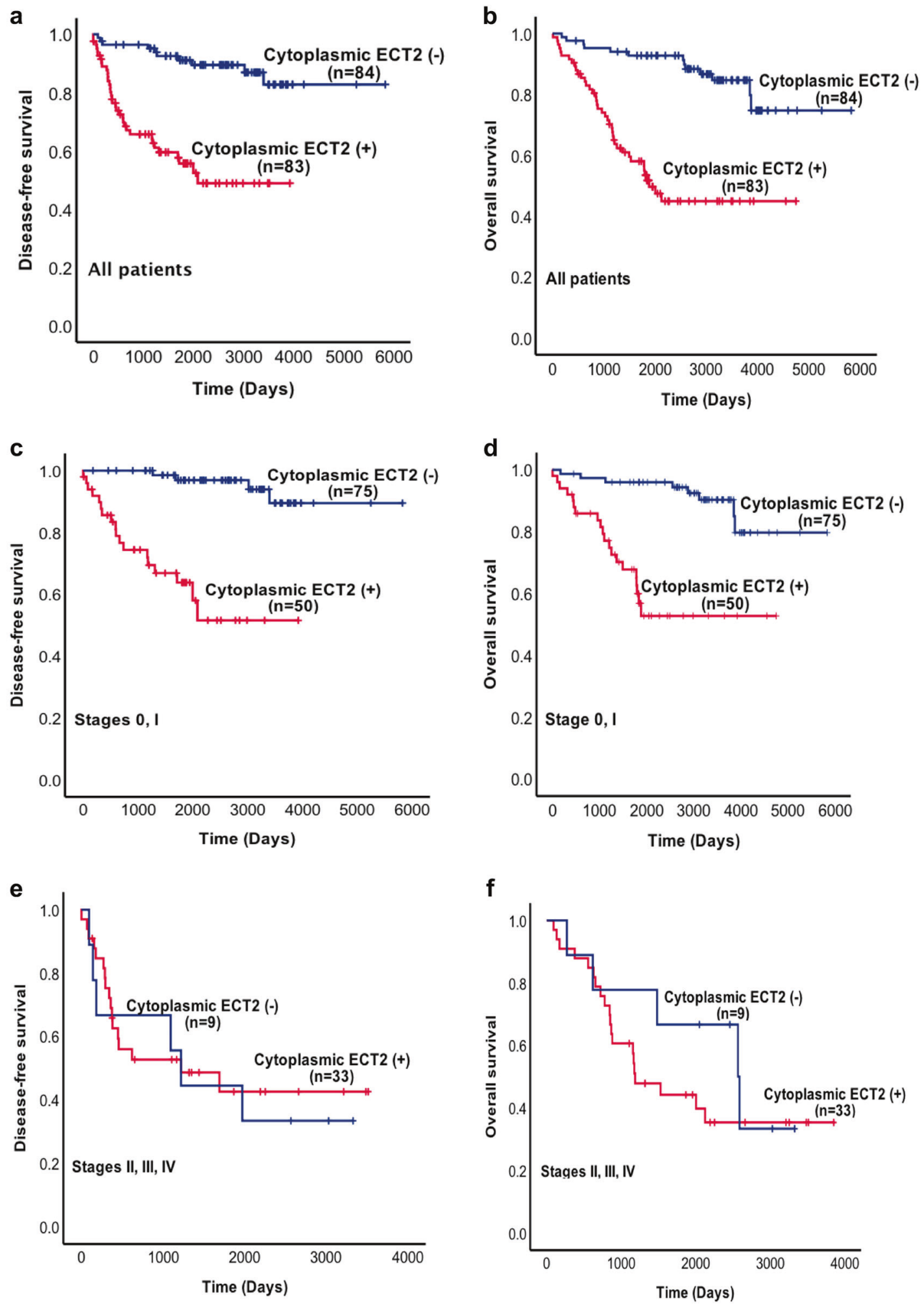

Fig. 5 Kaplan-Meier survival curves showing disease-free survival (DSF) and overall survival (OS) of patients with lung adenocarcinoma. a, b Cytoplasmic expression of ECT2 was significantly associated with poor survival in terms of both DFS and OS in all lung adenocarcinoma patients (both $P<0.001$ ). c, d Kaplan-Meier survival curves of patients with early stages $(0$ and $\mathrm{I})$ were significantly lower in patients

with positive cytoplasmic ECT2 expression in terms of both DSF and OS (both $P<0.001$ ). e, f Kaplan-Meier survival curves of patients with advanced stages (II, III, and IV). There were no significant differences between the groups with cytoplasmic positivity and negativity for ECT2 in terms of both DFS and OS $(P=0.768, P=0.463)$, respectively 
Table 3 Univariate and multivariate analysis of overall survival (Cox proportional hazards model)

\begin{tabular}{|c|c|c|c|c|c|c|}
\hline \multirow[t]{2}{*}{ Factors } & \multicolumn{3}{|c|}{ Univariate } & \multicolumn{3}{|c|}{ Multivariate } \\
\hline & HR & $95 \% \mathrm{CI}$ & $P$-value & HR & $95 \% \mathrm{CI}$ & $P$-value \\
\hline Age, years $(\geq 60$ vs $<60)$ & 1.088 & $0.546-2.169$ & 0.81 & & & \\
\hline Gender (male vs female) & 0.398 & $0.221-0.717$ & 0.002 & 0.94 & $0.470-1.881$ & 0.862 \\
\hline Lymphatic permeation $(-$ vs +$)$ & 0.199 & $0.112-0.351$ & $<0.001$ & 0.4 & $0.194-0.823$ & 0.013 \\
\hline Vascular invasion $(-$ vs + ) & 0.186 & $0.106-0.328$ & $<0.001$ & 0.577 & $0.280-1.188$ & 0.136 \\
\hline Pleural invasion (0 vs $1,2,3)$ & 0.218 & $0.126-0.375$ & $<0.001$ & 0.573 & $0.297-1.107$ & 0.097 \\
\hline Pathological stage (stage 0,1 vs other) & 0.22 & $0.126-0.382$ & $<0.001$ & 1.04 & $0.510-2.121$ & 0.915 \\
\hline Cytoplasmic ECT2 expression (-) vs (+) & 5.396 & $2.836-10.267$ & $<0.001$ & 2.584 & $1.124-5.939$ & 0.025 \\
\hline
\end{tabular}

Bold font indicates statistical significance

$H R$ hazard ratio, $95 \%$ CI 95\% confidence interval expression of P-ECT2(T790) tended to be negative (Figs. 7c, d, and Table 4). The cut-off used to define cytoplasmic ECT2 and P-ECT2(T790) positivity was $\geq 10$, as described in Materials and methods section.

\section{Discussion}

The prognostic significance of ECT2 expression has been confirmed in various aggressive malignancies, and therefore ECT2 is considered to be a very promising target for cancer therapy $[10,27,28]$. In this study, we first confirmed the correlation between ECT2 amplification and overexpression, we also explored the oncogenic functions of ECT2 in lung adenocarcinoma cells (Figs 1,2). Our data showed that suppression of ECT2 significantly reduced cell growth, motility, invasion, and the MAPK pathway of lung adenocarcinoma cells. These results were consistent with previous reports $[10,13,14,19,29]$ and suggest the important roles of ECT2 in cancer cells.

It has also been proposed that the subcellular localization of ECT2 protein is critical for its oncogenic functions [14, $19,29,30]$. In this study, we investigated the cytoplasmic expression of ECT2 protein and its correlation with outcomes in patients with lung adenocarcinoma (Figs 3, 4, 5 and Table 1). Our data suggested that ECT2 shows alterations in its expression and localization in lung adenocarcinoma, moving into the cytoplasm in more aggressive tumors. Cytoplasmic expression of ECT2 was evident in a substantial proportion of invasive adenocarcinomas, and was significantly correlated with tumor size, pathological stage, pleural invasion, vascular invasion, and lymphatic permeation, suggesting a potential role in tumor development and progression (Table 2). Furthermore, cytoplasmic ECT2 expression was significantly associated with poor survival in patients with lung adenocarcinoma, and multivariate analysis using the Cox proportional hazards model showed that it was an independent prognostic factor (Table 3). Collectively, these findings indicate that cytoplasmic ECT2 expression is strongly correlated with patient outcomes.

The present findings support previous evidence to indicate that ECT2 protein plays an important role as an oncoprotein when localized to the cytoplasm $[19,30]$. Several experimental studies have suggested that the Nterminally truncated ECT2 retains the GEF domain or that mutations at NLSs become mislocalized to the cytoplasm, activating Rho GTPases and leading to malignant transformation [16, 17, 31]. In addition, the ECT2 gene is localized to chromosome $3 \mathrm{q} 26$, and amplification of this region is often observed in lung squamous cell carcinomas $[32,33]$. Our previous study showed that ECT2 amplification was associated with overexpression of the protein in surgically resected lung adenocarcinomas [10]. Consistent with this notion, we found that lung adenocarcinoma cell lines showing ECT2 overexpression and amplification were characterized by increased levels of cytoplasmic ECT2 expression. On the other hand, nuclear ECT2 is thought to be an inactive form during interphase due to interaction between the $\mathrm{N}$-terminal domain and the GEF catalytic domain; this may segregate ECT2 from Rho GTPases, and inhibit its GEF activity $[11,21]$. However, other studies have shown that nuclear ECT2 functions to regulate cell-cycle progression: the expression of ECT2 increases at the onset of DNA synthesis and remains elevated during the $\mathrm{G} 2$ and $M$ phases [34-36]. Also, ECT2 is known to be negatively regulated by p53 and required for transition from the $\mathrm{G} 1$ to $\mathrm{S}$ phase in a lung carcinoma cell line [37]. These reports suggest that nuclear expression of ECT2 is a useful biomarker of cell proliferation. Moreover, we have previously demonstrated that overexpression of ECT2 protein is correlated with the proliferation index (Ki-67) and mitotic index in lung adenocarcinoma [10]. In this report, we showed that the prognostic implication of total ECT2 (ECT2+) (both the nuclear and mixed cytoplasmic/nuclear staining) was similar to the positive cytoplasmic expression (Supplementary Fig. 4). We believe that both the total and 
Fig. 6 Expression of ECT2 phosphorylated at T790 in lung adenocarcinoma cell lines. a Suppression of P-ECT2(T790) and ECT2 by ECT2 siRNA in Calu-3 cells was confirmed by western blotting. $\mathrm{M}$ indicates a molecular weight marker. b Suppression of ECT2 by ECT2 siRNA in Calu-3 cells was confirmed by RT-PCR. *Significantly different from siCON at $P<0.001$ (Student's $t$-test). Error bars represent mean $\pm \mathrm{SD}, n=3$. c Equal amounts of total cell lysate from PL16B, NCI-H23, and Calu-3 cells were immunoprecipitated with anti-ECT2 antibody, followed by immunoblotting with antibody against P-ECT2 (T790). IgG was used as a negative control; whole-cell lysate was used as a positive control. d P-ECT2(T790) in three cell lines (PL16B, NCIH23, and Calu-3) was normalized to total immunoprecipitated ECT2. Quantification of western blots was representative as mean \pm $\mathrm{SD}, n=3, P<0.03$ (one-way ANOVA). e

Immunocytochemical staining of Calu-3 and PL16B cells with antibody against P-ECT2(T790). $\times 400$ magnification, scale bar, $20 \mu \mathrm{m} . \times 1000$ magnification, scale bar, $10 \mu \mathrm{m}$ a
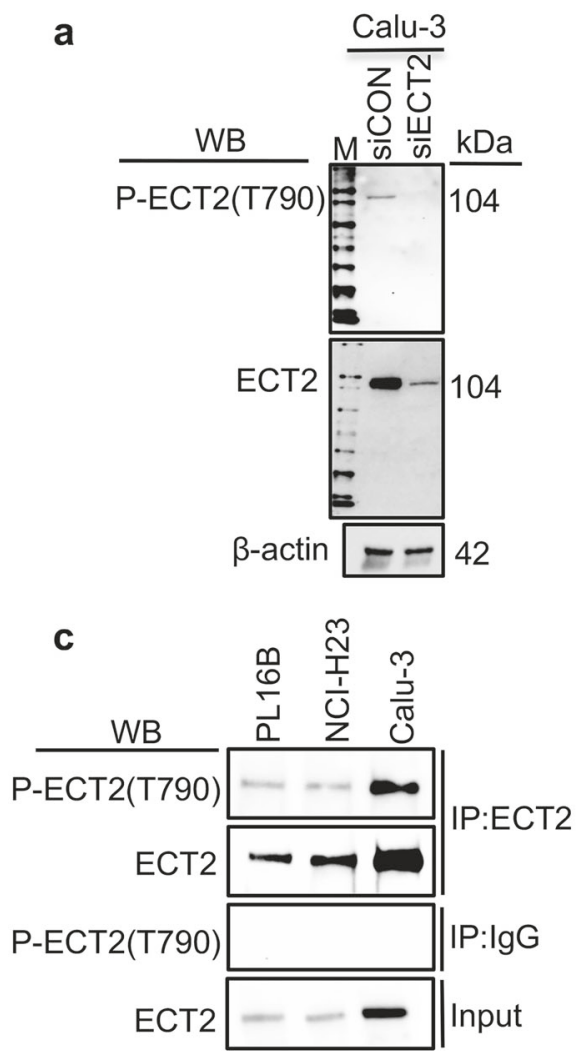

b

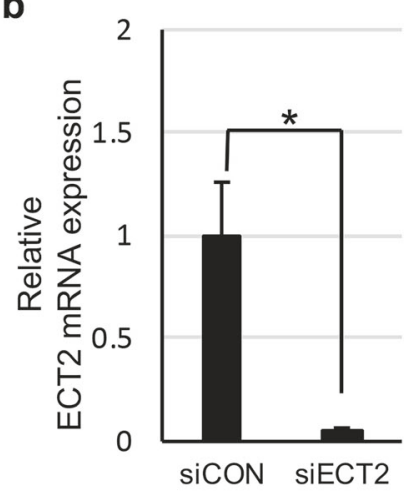

d

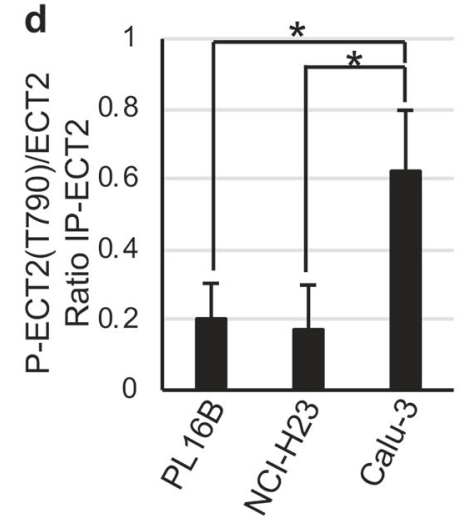

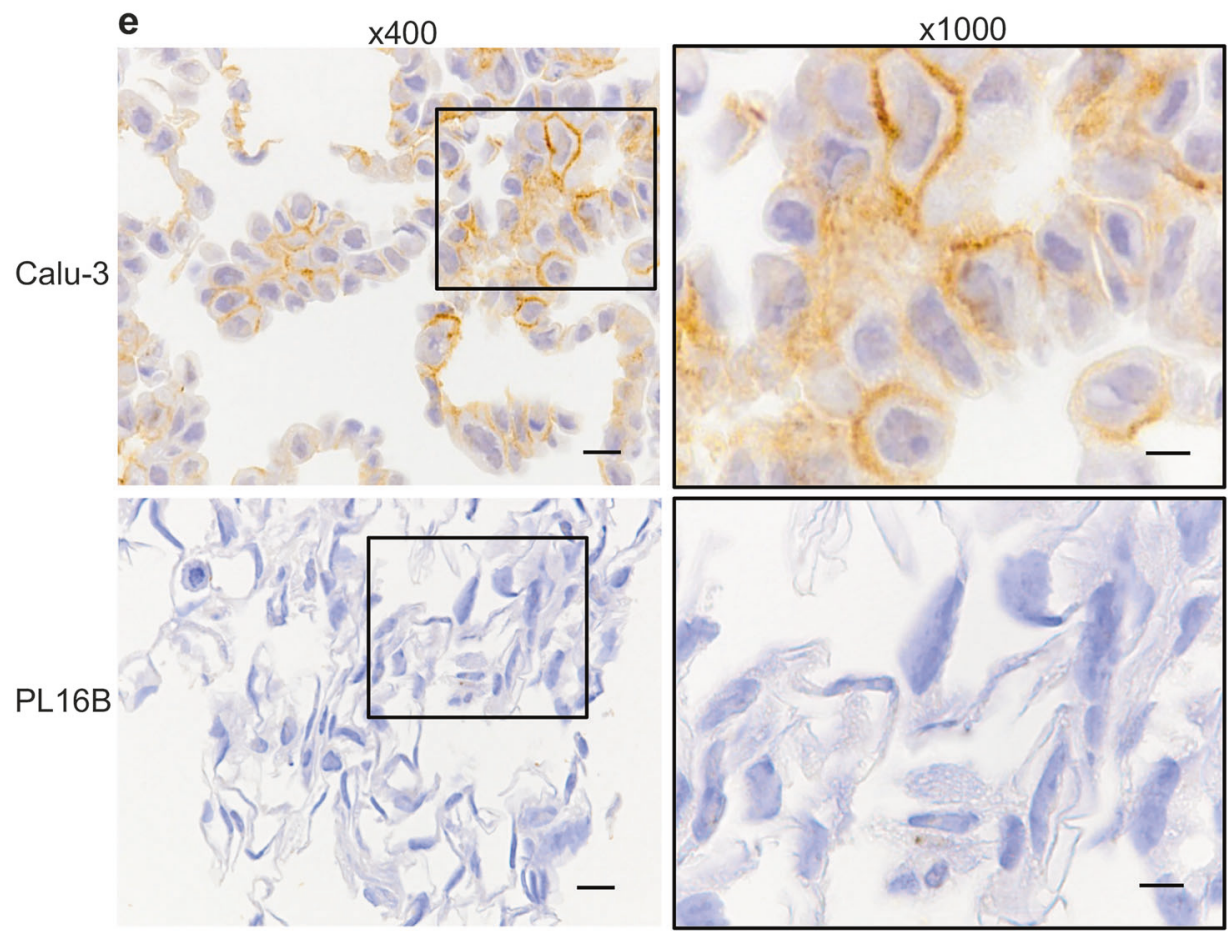

cytoplasmic ECT2 expressions are prognostic factors, but previous findings and our present results indicate that the forms of ECT2 protein expressed in the nucleus and the cytoplasm are functionally different, the former being a biomarker of cell proliferation and the latter one of cancer progression. 
Fig. 7 Phosphorylation of ECT2 at $\mathrm{T} 790$ in scraping cytology specimens.

Immunocytochemical images of two scraping cytology preparations from lung adenocarcinoma cases showing nuclear and cytoplasmic ECT2 positivity $(\mathrm{N}+\mathrm{C})$ or nuclear ECT2 positivity only (N). Two cases were stained with antiECT2 antibody (a, c) and with P-ECT2(T790) antibody (b, d). $\times 400$ magnification, scale bar, $20 \mu \mathrm{m}$

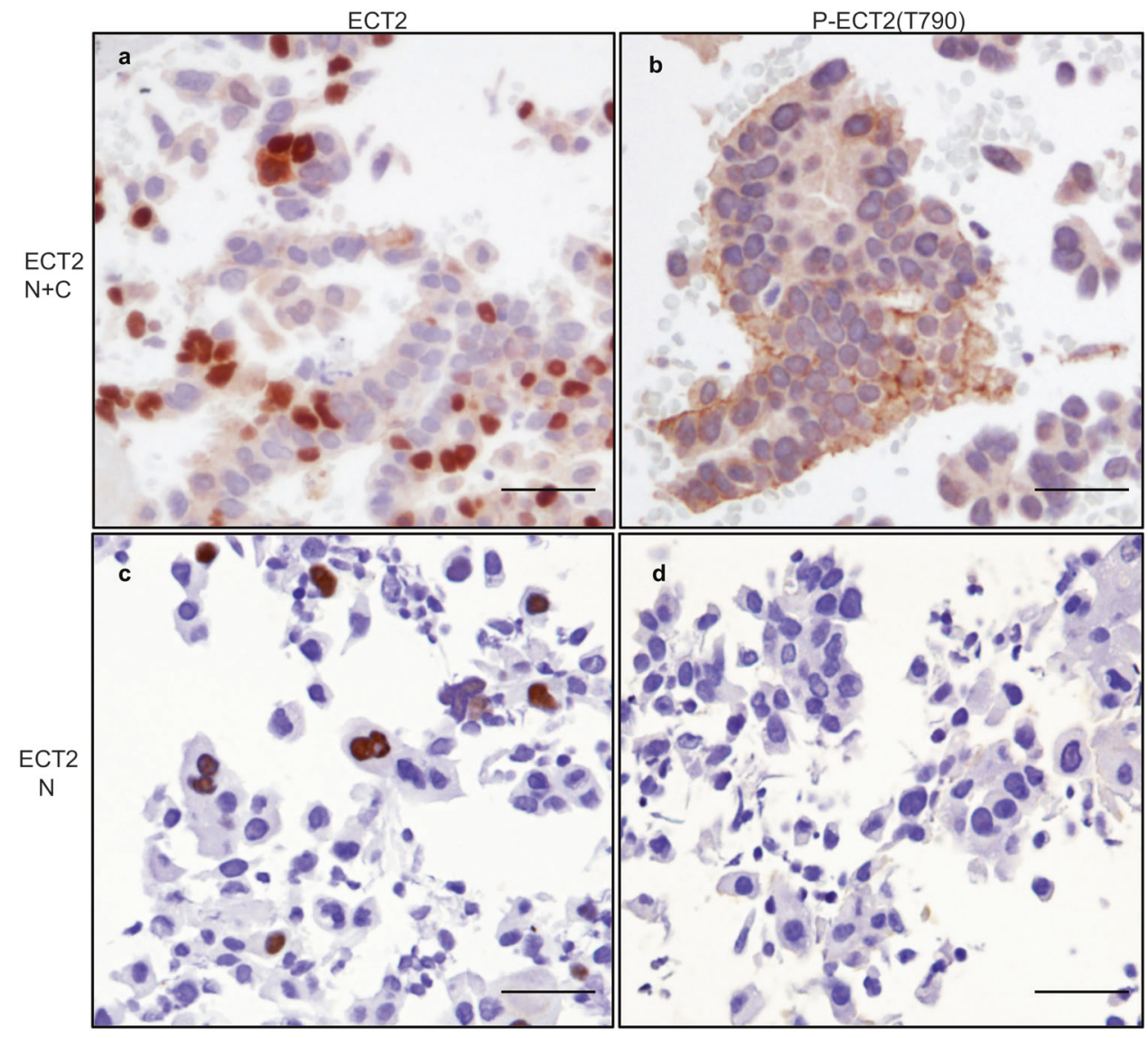

Table 4 Correlation between cytoplasmic ECT2 expression and PECT2 (T790)

\begin{tabular}{llll}
\hline $\begin{array}{l}\text { Phospho-ECT2 } \\
\text { (T790) staining }\end{array}$ & $\begin{array}{l}\text { No. of } \\
\text { cases }\end{array}$ & $\begin{array}{l}\text { Nuclear } \\
\text { ECT2 }\end{array}$ & Cytoplasmic ECT2 \\
\hline Positive & 6 & $(+)$ & $(+)$ \\
Negative & 7 & $(+)$ & $(-)$ \\
\hline
\end{tabular}

Nuclear: positive ECT2 staining only in the nucleus. Cytoplasmic: positive ECT2 staining in both the nucleus and cytoplasm. P-ECT2 (T790) positivity was evident in the cytoplasm, along with some membrane staining. Negative P-ECT2 (T790) expression was absent in the nucleus, cytoplasm, and membrane

Although nuclear ECT2 expression can be detected in both adenocarcinoma cells and normal bronchial cells, cytoplasmic ECT2 expression is expressed specifically in lung adenocarcinoma cells. Therefore, cytoplasmic ECT2 is likely to be a promising target for anticancer therapy. To date, no somatic mutations of the ECT2 gene have been identified in various cancers, including lung cancer. However, the molecular mechanism whereby ECT2 is exported from the nucleus to the cytoplasm and its role in tumor progression remain unclear. Further research will be needed to clarify these processes in lung adenocarcinoma.
Western blotting analysis indicated that ECT2 expressed in the cytoplasm of Calu-3, A549, and NCI-H2342 cells did not show truncation or other structural abnormalities (Fig. 3). Therefore, we further investigated the correlation between cytoplasmic expression of ECT2 and its phosphorylation status at T790. T790 lies within the C-terminal tail region of the ECT2 protein, and deletion of this region has been shown to reduce cellular transformation and Rac1 activity in vitro [17, 31]. In addition, expression of mutated ECT2 consisting of the DH/PH/C domain has been shown to lead to lamellipodia formation with Rac1 activation [31]. These data suggest the critical roles of the $\mathrm{C}$ domain in ECT2 cytoplasmic mislocalization and its GEF activity on Rho GTPases. Another study has shown that ECT2 interacts with Rho-RASL2 at the membrane ruffles of mesenchymal glioma cells, and that this interaction may modulate ECT2 (GEF) activity and drive invasive glioma cells [30]. The same group has reported that ECT2 colocalizes with Rac1 and $\mathrm{Cdc} 42$ at the leading edge of migrating astrocytoma cells, and that stable knockdown of ECT2 by shECT2 reduces the activities of both Rac1 and Cdc42, suggesting that the action of ECT2 (GEF) on Rho GTPases promotes the migration and invasive of astrocytoma cells [30].

Our data demonstrated that ECT2 is highly phosphorylated at T790 in both lung adenocarcinoma cell line and 
tumor cells obtained by scraping cytology (Figs 6, 7). Phosphorylation of ECT2 at T790 was evident in the cytoplasm along with some membrane staining of lung adenocarcinoma cells. We also found that phosphorylation of ECT2 at T790 was correlated with its cytoplasmic and membrane localization, suggesting that the T790 phosphorylation site may be a requirement for cytoplasmic and membrane localization of ECT2. In addition, previous reports have shown that ECT2 regulates its activities through phosphorylation on several residues [11, 21-23]. Consistently, we found that ECT2 in the cytoplasm and membrane, but not the nucleus, was highly phosphorylated at T790, possibly indicating that cytoplasmic and membrane ECT2 is an active form of the protein. Moreover, it is plausible that phosphorylation of cytoplasmic and membrane ECT2 is a specific event that catalyzes nucleotide exchange activity on Rac1, perhaps facilitating the progression of lung adenocarcinoma. Interestingly, our data showed that all cell lines and resected lung adenocarcinomas had cytoplasmic positive for ECT2 were also positive for the nucleus (Fig. 3, and Tables 1, 4). These results may suggest that overexpression of ECT2 in the nucleus causes its translocation to the cytoplasm, where it acquires its oncogenic function.

In conclusion, to our knowledge, we have demonstrated for the first time that cytoplasmic expression of ECT2 is a characteristic of lung adenocarcinoma with an aggressive malignant phenotype, particularly at the invasive stage, being linked to phosphorylation at T790 and associated with a poor prognosis. Our results suggest that cytoplasmic ECT2 could functionally facilitate the malignant progression of lung adenocarcinoma. Examination of a larger series of patients with lung adenocarcinoma may help to clarify whether phosphorylation of ECT2 at T790 could serve as a potent therapeutic target for such patients.

Acknowledgements We thank Dr. Shingo Sakashita for research support. We also thank Mr. Rayan Edbert Husni for his advice with statistical analysis using SPSS.

\section{Compliance with ethical standards}

Conflict of interest The authors declare that they have no conflict of interest.

\section{References}

1. Travis WD, Travis LB, Devesa SS. Lung cancer. Cancer. 1995;75:191-202.

2. Travis WD, Brambilla E, Noguchi M, et al. International Association for the Study of Lung Cancer/American Thoracic Society/ European Respiratory Society: international multidisciplinary classification of lung adenocarcinoma: executive summary. Proc Am Thorac Soc. 2011;8:381-5.
3. Cancer Genome Atlas Research N. Comprehensive molecular profiling of lung adenocarcinoma. Nature. 2014;511:543-50.

4. Paez JG, Janne PA, Lee JC, et al. EGFR mutations in lung cancer: correlation with clinical response to gefitinib therapy. Science. 2004;304:1497-1500.

5. Reynolds SH, Anna CK, Brown KC, et al. Activated protooncogenes in human lung tumors from smokers. Proc Natl Acad Sci USA. 1991;88:1085-9.

6. Kwak EL, Bang YJ, Camidge DR, et al. Anaplastic lymphoma kinase inhibition in non-small-cell lung cancer. N Engl J Med. 2010;363:1693-703.

7. Allemani C, Weir HK, Carreira H, et al. Global surveillance of cancer survival 1995-2009: analysis of individual data for 25,676,887 patients from 279 population-based registries in 67 countries (CONCORD-2). Lancet. 2015;385:977-1010.

8. Sahai E, Marshall CJ. RHO-GTPases and cancer. Nat Rev Cancer. 2002;2:133-142.9.

9. Porter AP, Papaioannou A, Malliri A. Deregulation of Rho GTPases in cancer. Small GTPases 2016;7:123-38.

10. Murata Y, Minami Y, Iwakawa R, et al. ECT2 amplification and overexpression as a new prognostic biomarker for early-stage lung adenocarcinoma. Cancer Sci. 2014;105:490-7.

11. Tatsumoto T, Xie XZ, Blumenthal R, et al. Human ECT2 is an exchange factor for Rho GTPases, phosphorylated in G2/M phases, and involved in cytokinesis. J Cell Biol. 1999;147:921-7.

12. Miki T, Smith CL, Long JE, et al. Oncogene Ect2 is related to regulators of small Gtp-binding proteins. Nature. 1993;362:462-5.

13. Hirata D, Yamabuki T, Miki D, et al. Involvement of epithelial cell transforming sequence-2 oncoantigen in lung and esophageal cancer progression. Clin Cancer Res. 2009;15:256-66.

14. Huff LP, Decristo MJ, Trembath D, et al. The role of Ect2 nuclear RhoGEF activity in ovarian cancer cell transformation. Genes Cancer. 2013;4:460-75.

15. Salhia B, Tran NL, Chan A, et al. The guanine nucleotide exchange factors trio, Ect2, and Vav3 mediate the invasive behavior of glioblastoma. Am J Pathol. 2008;173:1828-38.

16. Kim JE, Billadeau DD, Chen JJ. The tandem BRCT domains of Ect2 are required for both negative and positive regulation of Ect2 in cytokinesis. J Biol Chem. 2005;280:5733-9.

17. Saito S, Liu XF, Kamijo K, et al. Deregulation and mislocalization of the cytokinesis regulator ECT2 activate the Rho signaling pathways leading to malignant transformation. J Biol Chem. 2004;279:7169-79.

18. Yuce O, Piekny A, Glotzer M. An ECT2-centralspindlin complex regulates the localization and function of RhoA. J Cell Biol. 2005; 170:571-82.

19. Justilien V, Fields AP. Ect2 links the PKCiota-Par6alpha complex to Rac1 activation and cellular transformation. Oncogene. 2009;28:3597-607.

20. Liot C, Seguin L, Siret A, et al. APC(cdh1) mediates degradation of the oncogenic Rho-GEF Ect2 after mitosis. PLoS One. 2011;6: e23676.

21. Hara $\mathrm{T}$, Abe $\mathrm{M}$, Inoue $\mathrm{H}$, et al. Cytokinesis regulator ECT2 changes its conformation through phosphorylation at Thr-341 in G2/M phase. Oncogene. 2006;25:566-78.

22. Niiya F, Tatsumoto T, Lee KS, et al. Phosphorylation of the cytokinesis regulator ECT2 at G2/M phase stimulates association of the mitotic kinase Plk1 and accumulation of GTP-bound RhoA. Oncogene. 2006;25:827-37.

23. Justilien V, Jameison L, Der CJ, et al. Oncogenic activity of Ect2 is regulated through protein kinase $\mathrm{C}$ iota-mediated phosphorylation. J Biol Chem. 2011;286:8149-57.

24. Shimada A, Kano J, Ishiyama $\mathrm{T}$, et al. Establishment of an immortalized cell line from a precancerous lesion of lung adenocarcinoma, and genes highly expressed in the early stages of lung adenocarcinoma development. Cancer Sci. 2005;96:668-75. 
25. Burns JA, Li Y, Cheney CA, et al. Choice of fixative is crucial to successful immunohistochemical detection of phosphoproteins in paraffin-embedded tumor tissues. J Histochem Cytochem. 2009;57:257-64.

26. Iyoda $\mathrm{M}$, Kasamatsu $\mathrm{A}$, Ishigami $\mathrm{T}$, et al. Epithelial cell transforming sequence 2 in human oral cancer. PLoS ONE. 2010;5:e14082

27. Jin $\mathrm{Y}, \mathrm{Yu} \mathrm{YH}$, Shao QS, et al. Up-regulation of ECT2 is associated with poor prognosis in gastric cancer patients. Int $\mathrm{J}$ Clin Exp Pathol. 2014;7:8724-31.

28. Sano M, Genkai N, Yajima N, et al. Expression level of ECT2 proto-oncogene correlates with prognosis in glioma patients. Oncol Rep. 2006;16:1093-8.

29. Justilien V, Ali SA, Jamieson L, et al. Ect2-dependent rRNA synthesis is required for KRAS-TRP53-driven lung adenocarcinoma. Cancer Cell. 2017;31:256-69.

30. Weeks A, Okolowsky N, Golbourn B, et al. ECT2 and RASAL2 mediate mesenchymal-amoeboid transition in human astrocytoma cells. Am J Pathol. 2012;181:662-74.

31. Solski PA, Wilder RS, Rossman KL, et al. Requirement for C-terminal sequences in regulation of Ect2 guanine nucleotide exchange specificity and transformation. $\mathrm{J}$ Biol Chem. 2004;279:25226-33.

32. Brass N, Ukena I, Remberger K, et al. DNA amplification on chromosome 3q26.1-q26.3 in squamous cell carcinoma of the lung detected by reverse chromosome painting. Eur J Cancer. 1996;32:1205-8.

33. Fields AP, Justilien V, Murray NR. The chromosome $3 q 26$ OncCassette: a multigenic driver of human cancer. Adv Biol Regul. 2016;60:47-63.

34. David M, Petit D, Bertoglio J. Cell cycle regulation of Rho signaling pathways. Cell Cycle. 2012;11:3003-10.

35. Sakata H, Rubin JS, Taylor WG, et al. A Rho-specific exchange factor Ect2 is induced from $\mathrm{S}$ to $\mathrm{M}$ phases in regenerating mouse liver. Hepatology. 2000;32:193-9.

36. Fields AP, Justilien V. The guanine nucleotide exchange factor (GEF) Ect2 is an oncogene in human cancer. Adv Enzym Regul. 2010;50:190-200.

37. Scoumanne A, Chen XB. The epithelial cell transforming sequence 2, a guanine nucleotide exchange factor for Rho GTPases, is repressed by p53 via protein methyltransferases and is required for G(1)-S transition. Cancer Res. 2006;66:6271-9. 